\title{
1917: CONVERGÊNCIA DE INTERESSES, GOVERNO AUTORITÁRIO E MOVIMENTOS OPERÁRIOS
}

O assunto "Greves de 1917 no Rio Grande do Sul" foi importante variável para o estudo que, publicado em 1977 (1), demonstrou que a rede ferroviária gaúcha foi encampada em 1920 pelo Estado do RS a partir de premissas ideológicas positivistas, (constantes na base do Partido Republicano Riograndense e na Constituição Riograndense de 1891), e não, como até então propunha a tese vigente, somente como decorrência dos maus serviços da companhia arrendatária.

Naquele momento, já nos pareceu importante o estudo das greves, principalmente pelas suas relações com o poder constituído. Hoje, a importância da revisão e estudo de tal tema aumenta à medida que estão surgindo trabalhos que, ou colocam as greves gaúchas no mesmo nivel das ocorridas em outros Estados, ou enxergam nas mesmas conotações ideologico-politicas que, a nosso ver, absolutamente não existiram.

A República Velha assistiu ao aumento dos movimentos grevistas já ocorridos no período monárquico, em consequência dos crescimentos urbano e industrial, que submeteram número cada vez maior de individuos a precárias condições de trabalho e subsistência. Estas manifestações tiveram a sua base também na estruturação do mutualismo e sindicalismo, muitas vezes estribados em ideologias importadas da Europa.

Como diz Edgar Carone, «apesar da ação do proletário brasileiro ter refletido boa parte da complexidade ideológica e organizatória européia, não pòdemos deixar de lado os particularismos e, entre eles, principalmente as caracteristicas regionais (2).

Desta forma no RS, até 1917 as idéias anarquistas e socialistas incentivaram, com objetivos diferentes, aos movimentos grevistas,não sendo no entanto a base dos mesmos, devido justamente as caracteristicas de economia regional.

A primeira Guerra Mundial surpreendeu o Brasil em 1914, ocasionando primeiramente uma crise pela queda sintomática do comércio exterior e, posteriormente, um pseudo surto desenvolvimentista quando, carente de produtos de subsistência, a Europa passou a importá-los em grande quantidade. Neste período criaram-se indústrias e fomentou-se a agricultura, o que aumentou a demanda dos meios de transporte. Estes, que haviam surgido antes do processo de industrialização, à sombra do capital estrangeiro, estavam despre- 
parados para atender a tal demanda, entrando em crise.

No Rio Grande do Sul, desde 1905 a ferrovia estava unificada e arrendada à Compagnie Auxiliare de Chemins de Fer au Brésil que, mal administrada desde seu início teve, a partir de 1913, o controle acionário em poder do Sindicato Farquhar, mais propriamente da Brazil Railway. Por outro lado, a economia gaúcha estava ligada ao abastecimento interno do país desde a sua formação, estando de certa forma marginalizada dos lucros da região agro-exportadora. Em 1917, os reflexos desta dupla problemática se fizeram sentir sobre a massa trabalhadora gaúcha, levando-as aos movimentos paredistas. Baixos salários, aumento de serviços, acidentes de toda espécie e reclamações dos usuários levaram os operários de VFRGS à greve que eclodiu no dia 30 de julho de 1917. A situação dos trabalhadores de outras categorias do Estado em nada diferia dos da Viação e, por isto, houve imediata adesão das mesmas ao movimento.

Os operários da Viação Férrea procuraram a direção da Auxiliaire para entrar em acordo e enviaram à Presidência da República telegrama justificando o movimento (3). Os trabalhadores de outras categorias, reunidos sob a tutela da Federação Operária e sob a presidência do Sindicato dos Pedreiros e Classes Anexas, fundaram a Liga de Defesa Popular, que lançou (4) manifesto exigindo o barateamento de gêneros de primeira necessidade, aumento de $25 \%$ dos salários, generalização da jornada de 8 horas e de 6 horas para mulheres e crianças. Confundem-se, neste momento, as duas greves, cujo término ocorreu quando a direção da Viação Férrea prometeu aos operários aumento de salários e a Intendência de Porto Alegre e a Chefia de Polícia reuniram-se com os comerciantes, acertando as soluções para as demais categorias (5).

Quanto ao caráter ideológico dos movimentos, nota-se a influência anar-

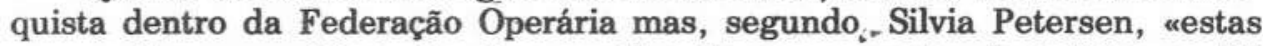
concepções anarquistas não são seguidas de uma maneira dogmática no RS como de resto aconteceu também nos outros estados brasileiros" (6). Os operários da Viação, por outro lado, fizeram questão de separar seu movimento das correntes políticas e ideológicas. Quando foram acusados de estarem sendo orientados por anarquistas e federalistas, procuraram a imprensa e o governo do Estado para esclarecer devidamente a situação (7).

A volta ao trabalho se fez paulatinamente em todos os setores mas, no ferroviário, nova greve iria ocorrer, desta vez com mais violência, no mes de outubro. No uacerton da Auxiliaire com os operários, ficara bem clara a impossibilidade da mesma em atender $o$ aumento de salários sem o aumento dos fretes. Como o último, por força de contrato, só seria possível com consentimento da União, os operários ficaram aguardando a solução do impasse até outubho, quando o atrazo do pagamento de seus salários e a percepção de que haviam sido vítimas da demagogia do Sr. Cartwright, diretor da empresa, os levaram à nova greve que estalou no dia 17 . Com a invasão da estação de Santa Maria, depredações e atos de violência, alastrou-se o movimento, que iria deixar apreensivos as classes econômicas e o poder político do Estado.

A imprensa riograndense desempenhou importante papel neste movimento, levando ao conhecimento público relatórios, balanços, quadros tarifários, manifestos e correspondência relativos à Auxiliaire (8), provocando com isto uma ação mais direta de Borges de Medeiros. Este, de 1905 até então, 
havia deixado que os acontecimentos evoluissem por si, só intervindo quando atingidas as bases positivistas do partido ou a Constituição do Estado. Aproveitou-se então o governo para, a partir dos boletins grevistas que davam eforas e morras aos estrangeiros como Carwright" (9), mostrar à União a inviabilidade de manter a VFRGS nas mãos da Auxiliaire.

Assim como em agosto, na greve de outubro o aumento das tarifas foi o ponto de apoio da direção da Viação para discutir o problema no momento da intervenção estatal. Achava a diretoria da ferrovia que, imputando ao Estado a culpabilidade de suas deficiências (pela interferência no congelamento/ de tarifas de 1911), (10) ficaria protegida perante o governo federal e perante o Sindicato Farquhar ao qual ainda pertencia.

Borges de Medeiros aceitou as acusações e, no momento oportuno, interferiu nas negociações, conseguindo um acordo com os operários. Armou um plano junto à Associação Comercial de Porto Alegre, que consistia em conceder aumento de tarifas depois de consulta prévia aos comerciantes de outras praças, indagando que produtos seriam taxados e qual o valor da taxação. (11) Em troca dã elevação de fretes, a Viação prometeu mais uma vez o aumento de salários.

Assumindo esta atitude paternalista, Borges de Medeiros grangeou a simpatia da camada operária e dos setores econômicos do Estado. Esta simpatia foi também decisiva, em termos de política riograndense, uma vez que a máquina eleitoral movimentava-se neste momento em direção à sucessão presidencial e, por conseguinte, ministerial, que deveria ocorrer no ano seguinte. O receio de uma sucessão presidencial favorável a Ruy Barbosa, o veterano contestador da Constituinte de 1891, fez com que o governo Borges de Medeiros buscasse, na resolução dos problemas do Estado, coesão interna e prestígio nas altas esferas políticas.

$\mathrm{O}$ atendimento ao pedido de reformulação do quadro tarifário da Viação Férrea satisfez a esses objetivos.

Neste momento, a Auxiliaire ficou numa situação delicada, pois não se justificaria que persistissem as más condições da estrada e dos serviços por ela prestados.

O Rio Grande do Sul ganhava mais um trunfo pela encampação de sua ferrovia, que iria ocorrer em 1920 , obedecendo aos ideais positivistas de autonomia Estadual, de socialização dos serviços públicos, de liberdade de comércio, de melhoria das condições de vida dos trabalhadores em geral, ideais estes também subentendidos no lema "Ordem e Progresso". (12)

As greves de 1917, fizeram convergir os interesses do Estado e de operários, comerciantes, industriais, agricultores e pecuaristas. As cisões políticas da classe dominante gaúcha ficaram adormecidas neste momento, para acirrarem-se novamente com a crise do pós guerra, rompendo o poder do PRR em 1923. (13)

Quanto aos operários que, em 1917, obtiveram a proteção de Borges de Medeiros, serão reprimidos em 1919 , pois as atitudes grevistas naquele momento não vem mais de encontro aos interesses no poder. 


\section{NOTAS}

(1) Kliemann, Luiza H. S. - "A Ferrovia Gaúcha nas diretrizes de Ordem e Progresso" in Revista de Estudos Ibero-Americanos PUC. Porto Alegre, $n^{\circ} 2$. Vol. III dez. 77.

(2) Carone, Edgar. - O Movimento Operário no Brasil, Corpo e Alma do Brasil, Difel 1979.

(3) Correio do Povo, 4 de agosto de 1917, p. 7.

(4) Echos do Sul, Rio Grande 2 de agosto de 19176 p. 2.

(5) Correio do Povo, Porto Alegre 9 de agosto de 1917 p. 5.

(6) Petersen, Silvia. - "As greves no Rio Grande do Sul» (1890-1919) in RS-Economia e Política, Série Documenta 2, Ed. Mercado Aberto.IP Alegre 1980.

(7) Correio do Povo, Porto Alegre 7 de agosto de 1917 p. 1

(8) É bastante extensa a documentaçăo a respeito existente nos jornais da época. Analizamos principalmente o Correio do Povo, A Federação e os Echos do Sul.

(9) Echos do Sul, Río Grande, 22 de outubro de 1917 p. 1.

(10) A Federação. - Porto Alegre Editoriais 1910.

(11) Arquivo da Associaçăo Comercial de Porto Alegre - Telegrama 2 de novembro de 1917.

(12) Kliemann, Luiza. op cit. 209.

(13) Antonacci, Maria Antonieta - "Aluta Oligárquica no Rio Grande do Sul na República velha» dissertaçăo de mestrado USP - Mimeografado. 